\title{
Sperm-Associated Antigen 4, a Novel Hypoxia-Inducible Factor 1 Target, Regulates Cytokinesis, and Its Expression Correlates with the Prognosis of Renal Cell Carcinoma
}

\author{
Kumi Shoji, ${ }^{*}$ Takashi Murayama, ${ }^{\dagger}$ Imari Mimura, ${ }^{* \ddagger}$ Takehiko Wada, ${ }^{*}$ Haruki Kume, ${ }^{\S}$ Akiteru Goto, ${ }^{\top \|}$ Takamoto Ohse, ${ }^{*}$ \\ Tetsuhiro Tanaka, ${ }^{*}$ Reiko Inagi, ${ }^{*}$ Frans A. van der Hoorn, ${ }^{* *}$ Ichiro Manabe, ${ }^{\dagger \dagger}$ Yukio Homma, ${ }^{\S}$ Masashi Fukayama, ${ }^{{ }^{\prime}}$ \\ Takashi Sakurai, ${ }^{\dagger}$ Takeshi Hasegawa, ${ }^{\ddagger \ddagger}$ Hiroyuki Aburatani, ${ }^{\ddagger}$ Tatsuhiko Kodama, ${ }^{\ddagger}$ and Masaomi Nangaku*
}

\begin{abstract}
From the Division of Nephrology and Endocrinology, ${ }^{*}$ Research Center for Advanced Science and Technology, ${ }^{\ddagger}$ and the Departments of Urology, ${ }^{\S}$ Pathology, "and Cardiovascular Medicine, ${ }^{\dagger \dagger}$ University of Tokyo, Tokyo, Japan; the Department of Pharmacology, Juntendo University School of Medicine, Tokyo, Japan; the Department of Cellular and Organ Pathology," Akita University Graduate School of Medicine, Akita, Japan; the Department of Biochemistry and Molecular Biology, ** Faculty of Medicine, University of Calgary, Calgary, Alberta, Canada; and the Division of Nephrology, ${ }^{\ddagger}$ Department of Medicine, Showa University Fujigaoka Hospital, Yokohama, Japan
\end{abstract}

\author{
Accepted for publication \\ February 21, 2013. \\ Address correspondence to \\ Masaomi Nangaku, M.D., Ph.D. \\ Division of Nephrology and \\ Endocrinology, University of \\ Tokyo, 7-3-1 Hongo, Bunkyo- \\ ku, Tokyo, Japan. E-mail: \\ mnangaku-tky@umin.ac.jp.
}

\begin{abstract}
Hypoxia plays a crucial role in many pathophysiological conditions, including cancer biology, and hypoxiainducible factor (HIF) regulates transcriptional responses under hypoxia. To elucidate the cellular responses to hypoxia, we performed chromatin immunoprecipitation with deep sequencing in combination with microarray analysis and identified HIF-1 targets. We focused on one of the novel targets, spermassociated antigen 4 (SPAG4), whose function was unknown. SPAG4, an HIF-1-specific target, is upregulated in various cultured cells under hypoxia. Examination of SPAG 4 expression using a tissue microarray consisting of 190 human renal cell carcinoma (RCC) samples revealed that SPAG4 is an independent prognostic factor of cancer-specific mortality. Live-cell imaging revealed localization of SPAG4 at the intercellular bridge in telophase. We also studied cells in which SPAG4 was knocked down. Hypoxia enhances tetraploidy, which disturbs cell proliferation, and knockdown of SPAG4 increased tetraploid formation and decreased cell proliferation under both normoxic and hypoxic conditions. Studies using deletion mutants of SPAG4 also suggested the involvement of SPAG4 in cytokinesis. Microarray analysis confirmed dysregulation of cytokinesis-related genes by knockdown of SPAG4. In conclusion, SPAG4 is an independent prognostic factor in RCC and plays a crucial role in cytokinesis to defend against hypoxiainduced tetraploid formation. This defensive mechanism may promote survival of cancer cells under hypoxic conditions, thus leading to poor prognosis. (Am J Pathol 2013, 182: 2191-2203; http:// dx.doi.org/10.1016/j.ajpath.2013.02.024)
\end{abstract}

Hypoxia plays a crucial role in a number of physiological and pathophysiological phenomena, including cancer biology. Because the abnormal tumor microvasculature cannot provide a sufficient blood supply, hypoxia is a common characteristic of all solid tumors. ${ }^{1}$ Although hypoxia is inevitably deleterious to cells, including those in tumors, cancer cells show a range of genetic changes that enable them to adapt to hypoxic conditions and improve their survival.

A key transcription factor that regulates these responses to hypoxia is hypoxia-inducible factor (HIF), which composed of an $\alpha$ subunit (HIF-1 $\alpha$; HIF-2 $\alpha$, alias EPAS-1; or HIF-3 $\alpha$ ) and a $\beta$ subunit (HIF-1 $\beta$; alias ARNT). ${ }^{2}$ Although HIF-1 $\beta$ is constitutively present, the HIF- $\alpha$ subunits are highly unstable, except under low oxygen tension. The stability of an HIF- $\alpha$ subunit is determined mainly by its degradation by von HippelLindau protein (VHL) in an oxygen-dependent manner. ${ }^{3,4}$ Under hypoxic conditions, HIF- $\alpha$ escapes degradation and

Supported by Grant-in-Aids for Scientific Research 24390213 from the Japan Society for the Promotion of Science and grants from SENSHIN Medical Research Foundation (M.N.)

T.M. and I.M. contributed equally to this work. 
HIF activates the transcription of target genes with hypoxiaresponsive elements.

HIF plays a crucial role in tumorigenesis, and HIF- $1 \alpha$ and HIF- $2 \alpha$ are overexpressed in many human cancers, including renal cell carcinoma (RCC), as a result of intratumoral hypoxia and genetic alterations. ${ }^{5-7}$ Furthermore, these elevated levels correlate with cancer-related mortality and treatment failure. $^{8}$

To elucidate the cellular responses to hypoxia, we performed chromatin immunoprecipitation with deep sequencing (ChIPSeq) in combination with microarray analysis, and identified a number of novel HIF targets. One of the targets, SPAG4, was originally identified as a testis-specific protein localized to microtubule-containing spermatid structures. ${ }^{9,10}$ SPAG4 belongs to the family of SUN domain-containing proteins, and SUN is a conserved domain in eukaryotes. ${ }^{11-13}$ Recent studies demonstrated the ubiquitous expression of human SPAG4 in various normal tissues and neoplastic tissues at the mRNA level. ${ }^{14-16}$ Little, however, is known about its function. We investigated SPAG4 expression in RCC. We also performed functional analyses to reveal a biological function of SPAG4.

\section{Materials and Methods}

\section{Cell Culture and Hypoxic Conditions}

Human umbilical vascular endothelial cells (HUVECs; ATCC, Manassas, VA) were cultured in EGM-2 MV complete medium (Lonza Japan, Tokyo, Japan). HeLa cells and human kidney-2 (HK-2) cells were cultured in Dulbecco's modified Eagle's medium (Nissui Seiyaku, Tokyo, Japan) containing $10 \%$ fetal bovine serum. Cells were grown in a humidified, $5 \% \mathrm{CO}_{2}$-enriched atmosphere at $37^{\circ} \mathrm{C}$. Hypoxic conditions were established by exposure to $1.0 \% \mathrm{O}_{2}$ and $5 \% \mathrm{CO}_{2}$ in an multigas incubator (APM-30D; Astec, Fukuoka, Japan). The duration of hypoxic incubation was 24 hours, except as otherwise specified.

\section{ChIP-Seq Analysis}

We performed ChIP-Seq analysis using anti-HIF- $1 \alpha$ antibody (NB 100-134; Novus Biologicals, Littleton, CO) in HUVECs, as described previously. ${ }^{17} \mathrm{~A}$ next-generation sequencer (Genome Analyzer II; Illumina, San Diego, CA) was used, and all mapped sequences were analyzed using QuEST software version 2.4 (http://mendel.stanford. edu/SidowLab/downloads/quest $).{ }^{18}$

\section{DNA Microarray and Data Analyses}

Human Genome U133 Plus 2.0 microarrays (Affymetrix, Santa Clara, CA) were used. At 48 hours after transfection of siRNA, the treated cells were incubated for a further 24 hours under normoxia or hypoxia, and their gene expression profiles were examined as described previously. ${ }^{17}$ Preparation of cRNA and hybridization of probe arrays were performed according to the manufacturer's instructions. The raw data in the Affymetrix Human Genome U133 Plus 2.0 array were exported to GeneSpring GX software version 11.5 (Agilent Technologies, Santa Clara, CA) and were normalized by robust multiarray average (RMA) normalization algorithms. For identification of genes significantly altered by hypoxia, total detected entities were filtered by signal intensity value (upper cutoff, 100th percentile; lower cutoff, 20th percentile) and error (SD $<0.1)$ to remove very low signal entities and to select reproducible signal values of entities among the experiments.

To investigate biological functions associated with the gene lists, we used the Database for Annotation, Visualization and Integrated Discovery (DAVID), ${ }^{19,20}$ an online gene database provided by the NIH (version 6.7; http:// david.abcc.ncifcrf.gov). Benjamini and Hochberg false discovery rates ( $5 \%$ false positive discovery rate) were used to correct for multiple testing.

\section{siRNA Transfection}

siRNAs were obtained from Life Technologies-Invitrogen (Carlsbad, CA). Transfection was performed with Lipofectamine RNAiMax reagent in HUVECs and with Lipofectamine 2000 reagent in HeLa cells, according to the manufacturer's protocols (Life Technologies-Invitrogen). At 48 hours after transfection, siRNA-treated cells were processed for further experiments. The target sequences of siRNA were as follows: human HIF- $1 \alpha$, forward $5^{\prime}$-AUAUGAUUGUGUCUCCAGCGGCUGG- $3^{\prime}$ and reverse $5^{\prime}$-CCAGCCGCUGGAGACACAAUCAUAU- $3^{\prime}$; human HIF- $2 \alpha$, forward $5^{\prime}$-UACAUUUGCGCUCAGUGGCUUGUCC- $3^{\prime}$ and reverse 5'-GGACAAGCCACUGAGCGCAAAUGUA3'; human SPAG4-1, forward 5'-CCUCCAGGUUUAUGAUGAAACUGA- $3^{\prime}$ and reverse $5^{\prime}$-UUCAGUUUCAUCAUAAACCUGGAGG-3'; and human SPAG4-2, forward 5' ACUCCACAAGGAGGUGUCCACUGUU- $3^{\prime}$ and reverse $5^{\prime}$-AACAGUGGACACCUCCUUGUGGAGU- ${ }^{\prime}$. Stealth RNAi Negative Control Med GC Duplex 2 or 3 (Life Technologies-Invitrogen) was used as control.

\section{RNA Isolation and RT-qPCR}

RNA extraction, RT-PCR, and real-time quantitative RTPCR (RT-qPCR) were performed as described previously. ${ }^{21}$ Primer sequences were as follows: human SPAG4, forward $5^{\prime}$-ATGAGGATTTTGTGCGGAAG- $3^{\prime}$ and reverse $5^{\prime}$-GCGTAATCGTGGGATGTCTT- ${ }^{\prime}$; human HIF- $1 \alpha$, forward $5^{\prime}$-CGAGATGCAGCCAGATCTCGGCGAAGTAA-3' ${ }^{\prime}$ and reverse 5'-CTCTCATTTCCTCATGGTCACATGGATG-3'; human HIF- $2 \alpha$, forward $5^{\prime}$-GAAGTCCCGGGATGCTGCGCG-3' and reverse 5'-ACTATGTCCTGTTAGCTCCACCTGTG- ${ }^{\prime}$; and human $\beta$-actin (internal control), forward $5^{\prime}$-TCCCCCAACTTGAGATGTATGAAG- $3^{\prime}$ and reverse 5'-AACTGGTCTCAAGTCAGTGTACAGG- ${ }^{\prime}$. 


\section{Luciferase Reporter Assay}

To generate the human SPAG4-promoter-luc plasmid and $S P A G 4$-enhancer-luc plasmid, we isolated fragments from the human SPAG4 promoter from -1000 to +118 relative to the transcription start site, and from the enhancer from +1633 to +892 relative to the transcription start site by PCR, using human genomic DNA as template. We cloned these fragments into the pGL3-basic vector (Promega, Madison, WI). Mutagenesis was conducted using mutated primer pairs. HUVECs were transiently transfected with plasmid DNA using FuGENE HD reagent (Roche Applied Science, Mannheim, Germany; Indianapolis, IN), and luciferase activity was measured using a dual-luciferase assay kit by cotransfection with pRL-CMV (Promega) to normalize transfection efficiency, as described previously. ${ }^{17,22}$

\section{Immunoblotting}

Immunoblotting was performed as described previously. ${ }^{23}$ The primary antibodies used for immunoblotting were anti-SPAG4 (1:1000; sc-85927; Santa Cruz Biotechnology, Santa Cruz, CA) and anti-actin antibody (1:2000; A2066; Sigma-Aldrich, St. Louis, MO). Densitometry analysis was performed using ImageJ software version 1.47b (NIH, Bethesda, MD).

\section{Study Population}

The clinical and pathological data of 190 adult patients who had been diagnosed with sporadic clear cell RCC (ccRCC) and had been treated with partial or radical nephrectomy between 1998 and 2003 at the University of Tokyo Department of Urology were reviewed. The diagnosis of ccRCC was based on the evaluation of H\&E-stained sections by pathologists at the University of Tokyo in accordance with the World Health Organization classification. ${ }^{24}$ Tumor staging was revised according to the 2009 TNM staging system. ${ }^{25}$ Nuclear grading was based on the appearance of the nuclei of tumor cells and was categorized as grade 1 (nuclei of tumor cells were smaller than those of normal renal tubular cells), grade 2 (nuclei were the same size), or grade 3 (nuclei were larger, and sometimes pleomorphic and bizarre). ${ }^{26}$ The Eastern Co-operative Oncology Group (ECOG) scale was used to measure performance status (PS). ${ }^{27}$ Incidentaloma was defined as a renal tumor detected during evaluation or surveillance of an unrelated medical condition, and symptomatic tumor was defined as a renal tumor detected on evaluation of hematuria, ipsilateral flank pain, a mass, or systemic symptoms such as loss of appetite. ${ }^{28}$ Written informed consent was obtained from all participants, and institutional review board approval was obtained from the University of Tokyo.

\section{TMA and Immunohistochemical Analysis}

Tissue microarrays (TMAs) consisting of 190 sporadic ccRCC samples were constructed for the immunohistochemical analysis of SPAG4. All tissue samples were fixed in formalin and embedded in paraffin. Representative tissue areas were punched out of the paraffin block using a $2.0-\mathrm{mm}$ punch, and duplicate cores per sample were arrayed on a recipient paraffin block, to decrease sampling error.

Indirect immunoperoxidase staining was performed as described previously. ${ }^{29}$ The primary and secondary antibodies used in this analysis were anti-SPAG4 rabbit polyclonal antibody $(1: 3000)^{9}$ and biotinylated goat anti-rabbit IgG antibody (1:1000; BA-1000; Vector Laboratories, Burlingame, CA). TMAs were scored in a masked manner by two independent observers (K.S. and M.N.). For the few instances of discrepant scoring, a consensus score was determined.

\section{Plasmids and Stable Transfection}

cDNA encoding human SPAG4 was obtained from HUVECs by RT-PCR and was subcloned into pEGFP-N1 (Clontech Laboratories, Mountain View, CA) and pcDNA4/TO/mycHisA (Life Technologies-Invitrogen). cDNA encoding human calnexin was amplified from human embryonic kidney (HEK 293) cells by RT-PCR, and subcloned into the modified pIREShyg2 (Clontech) carrying PhiC31 attB sequence that had been excised from pJTI Fast DEST (Life TechnologiesInvitrogen). mCherry (the generous gift of Dr. Roger Tsien) ${ }^{30}$ was fused to the C terminus of calnexin or SPAG4. Deletion mutants of human SPAG4 were constructed by PCR using pEGFP-N1-human SPAG4 as a template.

Transient transfection was performed with Lipofectamine 2000 reagent (Life Technologies-Invitrogen). Stable transfectants of HeLa cells expressing tagged SPAG4 were generated using the Jump-In system (Life TechnologiesInvitrogen) according to the manufacturer's protocol. To generate double stable transfectants, HeLa cells stably expressing SPAG4-EGFP were cotransfected with the modified pIREShyg2 carrying calnexin-mCherry and pJTI PhiC31 (Life Technologies-Invitrogen).

\section{Live-Cell Imaging}

Live-cell imaging was performed with a high-speed confocal laser scanning microscope system, as described previously. ${ }^{31}$ HeLa cells were grown on collagen-coated glass-bottom dishes and were observed using a Nipkow-disk confocal laser scanning unit (CSU22; Yokogawa Electric, Tokyo, Japan) equipped with an argon-krypton ion laser (488 and $568 \mathrm{~nm}$ excitation). Images were acquired with an electron-multiplying charge-coupled device camera (EMCCD C9100; Hamamatsu Photonics, Shizuoka, Japan) at a rate of $466 \mathrm{~ms}$ per image. For multicolor observations, cells were observed using a W-view system (model 8509; Hamamatsu Photonics). For long-term live-cell imaging, cells were observed using a CellVoyager CV1000 confocal scanner system (Yokogawa). Images were acquired every 5 minutes at a rate of $200 \mathrm{~ms}$ per image.

To visualize tubulin structures during live-cell imaging, HeLa cells were transduced with CellLight Tubulin-RFP 
BacMam 2.0 (Life Technologies-Invitrogen) according to the manufacturer's protocol.

\section{Analysis of Tetraploid Formation by Flow Cytometry}

Cells were collected by trypsinization and were fixed with $70 \%$ ethanol overnight at $-20^{\circ} \mathrm{C}$. The cells were then stained with a solution containing $50 \mu \mathrm{g} / \mathrm{mL}$ propidium iodide (Dojindo Molecular Technologies, Kumamoto, Japan) and 5 $\mathrm{mg} / \mathrm{mL}$ RNase A (Sigma-Aldrich) in $0.1 \%$ bovine serum albumin in PBS for 20 minutes in the dark at room temperature. For each sample, 10,000 cells were analyzed using a flow cytometer (BD Biosciences, San Jose, CA), and data were collected using Cell Quest software (Becton Dickinson). The population of tetraploid cells was quantitated based on scatter analysis using ModFIT LT software version 3.1 (Verity Software House, Topsham, ME).

\section{Immunocytochemistry}

Cells were fixed with methanol/acetone (1:1) or $2 \%$ paraformaldehyde, followed by permeabilization with $0.3 \%$ Triton X-100 surfactant in PBS. After a washing, the cells were incubated with anti-c-Myc antibody (1:200; sc-40; Santa Cruz Biotechnology), anti- $\alpha$-tubulin antibody (1:1000; T6199; Sigma-Aldrich), or anti- $\beta$-catenin antibody (1:200; 610154; BD Biosciences). For c-Myc and $\alpha$-tubulin staining, anti-mouse IgG1-FITC antibody (1:200; 1070-02; SouthernBiotech, Birmingham, AL) was applied. For $\beta$-catenin, biotinylated anti-mouse $\operatorname{IgG}$ antibody (1:1000; BA-2001; Vector Laboratories) was applied, followed by Alexa Fluor 594-conjugated streptavidin (1:500; S-32356; Life Technologies-Invitrogen). Nuclei were stained with Hoechst 33342 dye (Sigma-Aldrich). An Eclipse E600 microscope (Nikon, Tokyo, Japan) was used for observation.

\section{BrdU Assay}

siRNA-treated HeLa cells were plated in $100 \mu \mathrm{L}$ of medium on 96-well plates. Forty-eight hours after plating, cell incorporation of bromodeoxyuridine (BrdU) was measured by enzyme-linked immunosorbent assay with a BrdU Labeling and Detection Kit III (Roche Applied Science) according to the manufacturer's protocol. Absorbance at $405 \mathrm{~nm}$ was measured using a Biochrom plate reader (Asys Hitech, Eugendorf, Austria; Cambridge, UK).

\section{Cell Proliferation Assay}

siRNA-treated HeLa cells were plated in $100 \mu \mathrm{L}$ of medium on 96-well plates. At 1, 24, 48, and 72 hours after plating, we performed CellTiter $96 \mathrm{AQ}_{\text {ueous }}$ one-solution cell proliferation assay (Promega) as described previously. ${ }^{21}$ Absorbance at $490 \mathrm{~nm}$ was measured using a Biochrom plate reader (Asys Hitech).

\section{Statistical Analysis}

All data are reported as means \pm SD. Data for two groups were analyzed with an unpaired $t$-test, and those for more than two groups were compared by analysis of variance with Tukey's post hoc test. Nonparametric data were analyzed with the $U$-test or Kruskal-Wallis test when appropriate. Cancer-specific survival was estimated using the KaplanMeier method. The log-rank test was used to compare survival between different groups. The Cox proportional hazards regression model was used to determine the effect of clinicopathological parameters on survival. The hazard ratio was used as a measure of risk of death in different categories. Differences with a $P$ value of $<0.05$ were considered significant. GraphPad Prism software version 5.04 for Windows (GraphPad Software, San Diego, CA) and JMP software version 9.0.0 (SAS Institute, Cary, NC) were used for data analysis.

\section{Results}

\section{SPAG4 Is a Novel HIF-1-Specific Target}

To elucidate the cellular responses to hypoxia, we performed ChIP-Seq analysis using HUVECs. ${ }^{17}$ We identified 2060 HIF-1 binding sites under hypoxia in HUVECs. We defined the nearest known transcript within $50 \mathrm{kbp}$ from the HIF-1 binding site as the corresponding gene. In this manner, the 2060 HIF-1 binding sites were matched to 1240 genes (Supplemental Table S1).

We also performed microarray analysis in HUVECs treated with control siRNA or siRNA targeting the HIF-1 $\alpha$ gene $(H I F 1 A)$, and examined gene expression profiles under both normoxia and hypoxia. ${ }^{17}$ Hypoxia-regulated probes were defined as having a $>1.0 \log _{2}$-fold up-regulation in the presence of control siRNA under hypoxia, compared with normoxia. To identify genes regulated by HIF-1, we set the following criteria for downstream HIF-1 targets: the base-2 logarithm of fold-change value was $>1.6$ in normoxia, compared with hypoxia, and the base-2 logarithm of foldchange value was $<1.2$ in control siRNA, compared with HIF-1 siRNA, under hypoxia. Using these criteria, we identified 276 genes that are regulated by HIF-1 directly or indirectly under hypoxia (Supplemental Table S2).

The overlap of the HIF-1 target genes identified in ChIPSeq and microarray analysis should correspond to genes that are regulated by HIF-1 directly, and we identified 78 such genes (Figure 1A and Supplemental Table S3). Among these targets, we focused on a novel HIF-1 target, SPAG4, because SPAG4 was the sixth highest gene in the increase rate of mRNA expression after 24 hours of hypoxia and because the function of the SPAG4 product was unknown.

We confirmed up-regulation of SPAG4 under hypoxia in HUVECs by RT-qPCR (Figure 1B). Our ChIP-Seq analysis showed HIF-1 binding in the enhancer of human SPAG4 gene (Figure 1C), and we investigated the HIF-1 dependency 
A

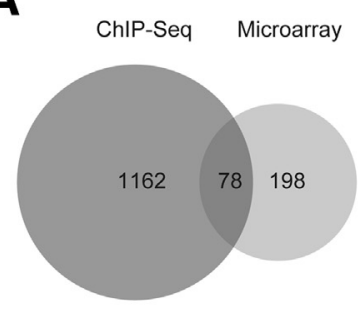

B

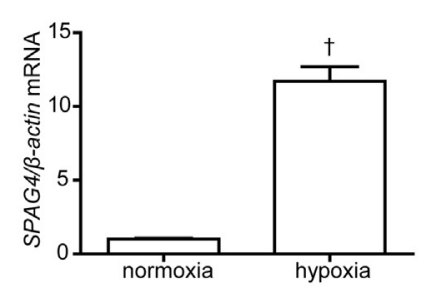

C

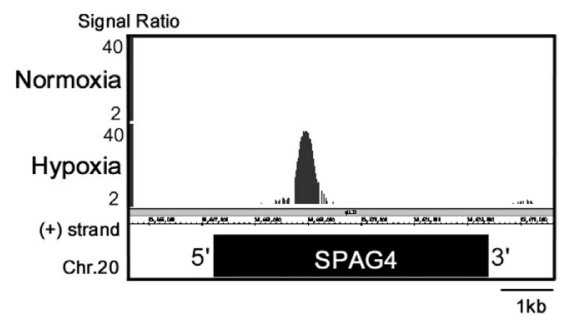

D

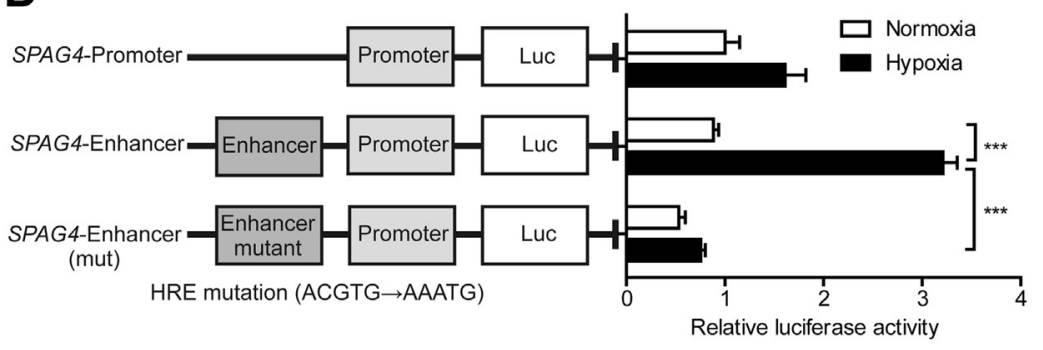

$\mathbf{F}$

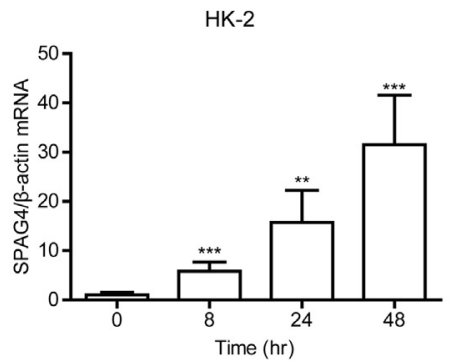

G

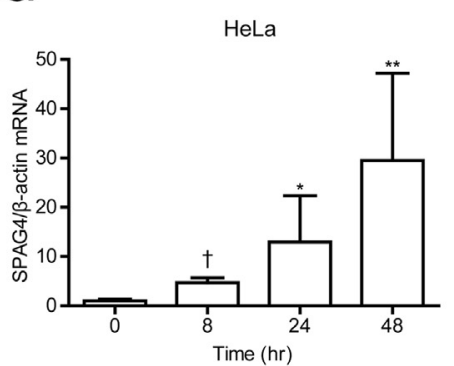

E

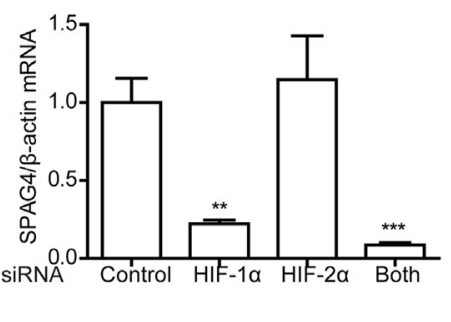

H $\quad$ HK-2

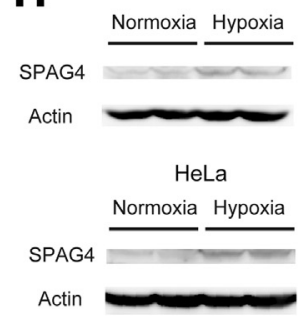

Figure 1 Identification of SPAG4 as a novel HIF-1 target. A: HIF-1 target genes were identified by two different methods in HUVECs: ChIP-Seq analysis and microarray analysis using siRNA targeting HIF-1 $\alpha$. The 78 overlapping genes (ie, genes identified with both methods) are directly regulated by HIF-1. B: RT-qPCR demonstrated up-regulation of SPAG4 mRNA levels under hypoxia in HUVECs. C: ChIP-Seq analysis with anti-HIF-1 $\alpha$ antibody indicated HIF-1 binding to one site in the enhancer region of SPAG4 gene under hypoxia. D: Luciferase reporter assay demonstrated the up-regulation of SPAG4 promoter activity by hypoxia via the hypoxia-responsive element at the enhancer of SPAG4. The design of luciferase vector PGL3 with the SPAG4 promoter and/or SPAG4 enhancer is shown at left, and the results in HUVECs are shown at the right. E: RT-qPCR showed that SPAG4 mRNA levels were regulated by HIF-1 $\alpha$, but not HIF-2 $\alpha$. F and G: SPAG4 mRNA expression, estimated by RT-qPCR, was up-regulated under hypoxia in a time-dependent manner in HK-2 cells (F) and HeLa cells (G). H: Immunoblotting analysis confirmed up-regulation of SPAG4 at the protein level under hypoxia in HK-2 cells and HeLa cells. The duration of hypoxic incubation was 48 hours. Data are expressed as means \pm SD. $n=3(\mathbf{B}, \mathbf{D}$, and $\mathbf{E})$ or 5 (F and $\mathbf{G})$ per group. ${ }^{*} P<0.05,{ }^{* *} P<0.01,{ }^{* * *} P<0.001$, and ${ }^{\dagger} P<0.0001$.

of SPAG4 regulation by luciferase reporter assay using this enhancer region. Addition of the SPAG4 enhancer to the SPAG4 promoter-luc resulted in the 3.6-fold up-regulation of reporter activity under hypoxia, compared with normoxia (Figure 1D). Furthermore, mutation of the hypoxia-responsive element motif of the SPAG4 enhancer (ACGTG $\rightarrow$ AAATG) resulted in a $76.5 \%$ reduction in reporter activity. These results demonstrated that a hypoxia-responsive element in the enhancer of SPAG4 is responsible for hypoxic induction.

To investigate whether SPAG4 is a specific target of HIF-1, we evaluated SPAG4 mRNA levels using siRNA targeting HIF- $1 \alpha$ or HIF- $2 \alpha$ under hypoxia. The knockdown efficiencies of HIF- $1 \alpha$ and HIF- $2 \alpha$ at the mRNA level were $83 \%$ and $90 \%$, respectively. SPAG4 mRNA levels were decreased only when $H I F-1 \alpha$ mRNA levels were suppressed (Figure 1E). These results suggest that SPAG4 expression is regulated by HIF-1, but not by HIF-2. An online database search using Gene Expression Omnibus profiles (GEO Profiles; http://www.ncbi.nlm.nih.gov/geoprofiles) revealed the same results in MCF-7 breast cancer cells (GEO profile records GDS2760 and GDS2761), showing HIF-1-specific regulation of SPAG4 without cell-type dependency. We also confirmed oxygen-dependent regulation of SPAG4 in other cell types, such as human proximal tubular epithelial HK-2 cells and human cervical cancer HeLa cell (Figure 1, F-H).

\section{SPAG4 Expression Is an Independent Prognostic Factor in $\mathrm{CCRCC}$}

Hypoxia plays a crucial role in cancer, and we decided to investigate SPAG4 expression in ccRCC. First, we performed an online database search using GEO Profiles and found up-regulation of SPAG4 in ccRCC, compared with healthy kidney (GDS505 and GDS2880). 
To confirm and extend these observations, we performed TMA analysis consisting of 190 ccRCC samples. Demographic and clinical characteristics of the patients are listed in Table 1. The median follow-up time was 98 months (range, 1 to 206 months); during follow-up, 33 (17.4\%) and $21(11.1 \%)$ of the patients died of cancer-specific causes and of other causes, respectively. The mean time to cancerspecific death was 22 months (range, 4 to 111 months). Cancer-specific survival for the whole group was $87.2 \%$ at 5 years and $79.3 \%$ at 10 years. Cancer-specific survival in our study population was dependent on TNM stage, nuclear grading, ECOG PS, and mode of presentation, which is consistent with previous reports ${ }^{28,32-34}$ (Figure 2, A-D).

In immunohistochemical analysis, only the intensity of SPAG4 staining was scored for each tissue (negative, score 0; low, score 1; high, score 2), because tumor cells stained homogeneously in each sample (Figure 2E). Of the 190 samples, $32(16.8 \%)$ were categorized as score 0,97 $(51.1 \%)$ as score 1 , and $61(32.1 \%)$ as score 2 . There was no significant difference in SPAG4 score between clinicopathological features except for nuclear grading (Table 1), which is a well-known prognostic factor of ccRCC..$^{32,33,35,36}$

Table 1 Characteristics of Patients in Tissue Microarray Analysis

\begin{tabular}{|c|c|c|c|}
\hline Variable & no. $(\%)$ & $\begin{array}{l}\text { SPAG4 score } \\
\text { (means } \pm \text { SD) }\end{array}$ & $P$ value \\
\hline Total & $190(100)$ & $1.15 \pm 0.68$ & \\
\hline \multicolumn{4}{|l|}{ Sex } \\
\hline Male & $144(75.8)$ & $1.17 \pm 0.67$ & \multirow[t]{2}{*}{0.6688} \\
\hline Female & $46(24.2)$ & $1.11 \pm 0.74$ & \\
\hline \multicolumn{4}{|l|}{ ECOG performance status } \\
\hline $\mathrm{PS}=0$ & $159(83.7)$ & $1.13 \pm 0.69$ & \multirow[t]{2}{*}{0.2325} \\
\hline $\mathrm{PS} \geq 1$ & $31(16.3)$ & $1.29 \pm 0.64$ & \\
\hline \multirow{2}{*}{\multicolumn{4}{|c|}{$\begin{array}{l}\text { Pathological TNM staging } \\
\text { pT }\end{array}$}} \\
\hline & & & \\
\hline $\mathrm{T} 1$ & $143(75.3)$ & $1.10 \pm 0.69$ & \multirow[t]{4}{*}{0.1944} \\
\hline T2 & $13(6.8)$ & $1.15 \pm 0.80$ & \\
\hline T3 & $32(16.8)$ & $1.38 \pm 0.61$ & \\
\hline T4 & $2(1.1)$ & $1.50 \pm 0.71$ & \\
\hline \multicolumn{4}{|l|}{$\mathrm{pN}$} \\
\hline $\mathrm{N} 0+\mathrm{NX}$ & $186(97.9)$ & $1.15 \pm 0.68$ & \multirow[t]{2}{*}{0.7239} \\
\hline $\mathrm{N} 1+\mathrm{N} 2$ & $4(2.1)$ & $1.25 \pm 0.96$ & \\
\hline \multicolumn{4}{|l|}{ pM } \\
\hline MO & $172(90.5)$ & $1.14 \pm 0.68$ & \multirow[t]{2}{*}{0.3812} \\
\hline M1 & $18(9.5)$ & $1.28 \pm 0.75$ & \\
\hline \multicolumn{4}{|l|}{ Overall staging } \\
\hline Stage I & $138(72.6)$ & $1.09 \pm 0.68$ & \multirow[t]{4}{*}{0.1724} \\
\hline Stage II & $11(5.8)$ & $1.09 \pm 0.83$ & \\
\hline Stage III & $24(12.6)$ & $1.38 \pm 0.58$ & \\
\hline Stage IV & $17(9.0)$ & $1.35 \pm 0.70$ & \\
\hline \multicolumn{4}{|l|}{ Nuclear grade } \\
\hline Grade 1 & $35(18.4)$ & $0.86 \pm 0.73$ & \multirow[t]{3}{*}{0.0226} \\
\hline Grade 2 & $125(65.8)$ & $1.21 \pm 0.66$ & \\
\hline Grade 3 & $30(15.8)$ & $1.27 \pm 0.64$ & \\
\hline \multicolumn{4}{|l|}{ Mode of presentation } \\
\hline Incidentaloma & $126(66.3)$ & $1.14 \pm 0.69$ & \multirow[t]{2}{*}{0.6141} \\
\hline Symptomatic tumor & $64(33.7)$ & $1.19 \pm 0.69$ & \\
\hline
\end{tabular}

Although the difference in cancer-specific mortality between SPAG4 score 1 and score 2 did not reach statistical significance, patients with higher SPAG4 score showed higher mortality (Figure 2F). Patients with SPAG4 expression (score 1 and score 2) showed significantly higher cancer-specific mortality than those without expression (score 0$)(P=0.0215)$ (Figure $2 \mathrm{G})$.

Univariate and multivariate analyses of significant clinicopathological factors are listed in Table 2. SPAG4 expression was a significant prognostic factor of cancer-specific deaths in both univariate and multivariate analyses. We further examined the significance of SPAG4 expression in the subgroup of nuclear grades 2 and 3 , because there was no cancer-specific death in the grade 1 population (Figure 2B). Demographic and clinical characteristics of the patients in this subgroup are listed in Supplemental Table S4. Patients with SPAG4 expression showed a trend toward poor cancerspecific mortality, compared with those without expression (Figure 2H), and even in this subgroup of malignant nuclear grading, SPAG4 was an independent prognostic factor in both univariate and multivariate analyses (Table 2).

\section{SPAG4 Localizes at the Intercellular Bridge during Telophase}

Our analysis of these 190 patients with ccRCC showed that SPAG4 is a significant prognostic factor. We decided to determine the biological role of SPAG4, and therefore studied subcellular localization of SPAG4 using HeLa cells as a representative epithelial cancer cell line. To perform live-cell imaging for this purpose, we generated a stable HeLa cell line expressing fluorescent SPAG4. EGFP was fused at the C-terminus of full-length SPAG4, and expression of the fused protein was confirmed using anti-SPAG4 antibody (Figure 3A). Live-cell imaging of SPAG4-EGFP HeLa cells with high-speed laser scanning confocal microscopy demonstrated localization of SPAG4 mainly at the endoplasmic reticulum (ER) in interphase (Figure 3B). It was confirmed that SPAG4 was colocalized with calnexin, an ER marker (Figure 3C).

The most conspicuous finding was localization of SPAG4 at the intercellular bridge during telophase (Supplemental Video S1). We confirmed this observation by transducing SPAG4-EGFP HeLa cells with fluorescent tubulin (Figure 3D). Furthermore, imaging of double stably transfected cells expressing both SPAG4-EGFP and calnexinmCherry showed that this structure was specific for SPAG4 and was not derived from the ER (Figure 3E). These data were obtained under normoxic conditions, for technical feasibility, but essentially the same results were confirmed under hypoxic conditions (data not shown).

Next, to examine the influence of the tag, we generated a stable HeLa cell line expressing c-Myc-tagged SPAG4 and then performed immunocytochemistry. Localization of c-Myc-tagged SPAG4 was consistent with that of SPAG4-EGFP during interphase and telophase (Figure 3F). 
A

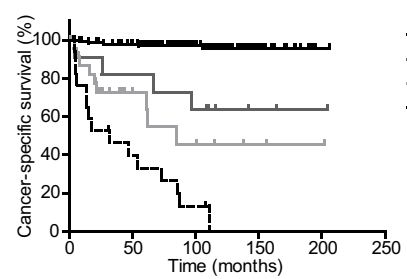

C

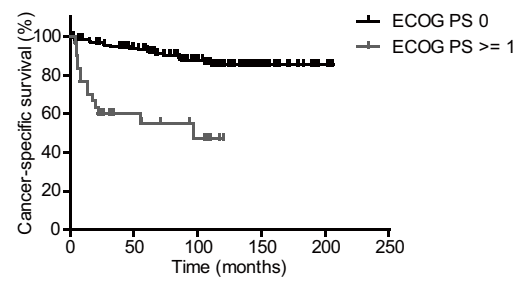

$\mathbf{E}$

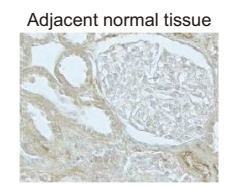

RCC-score 1

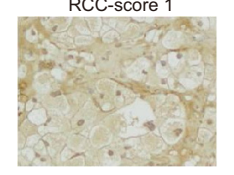

G
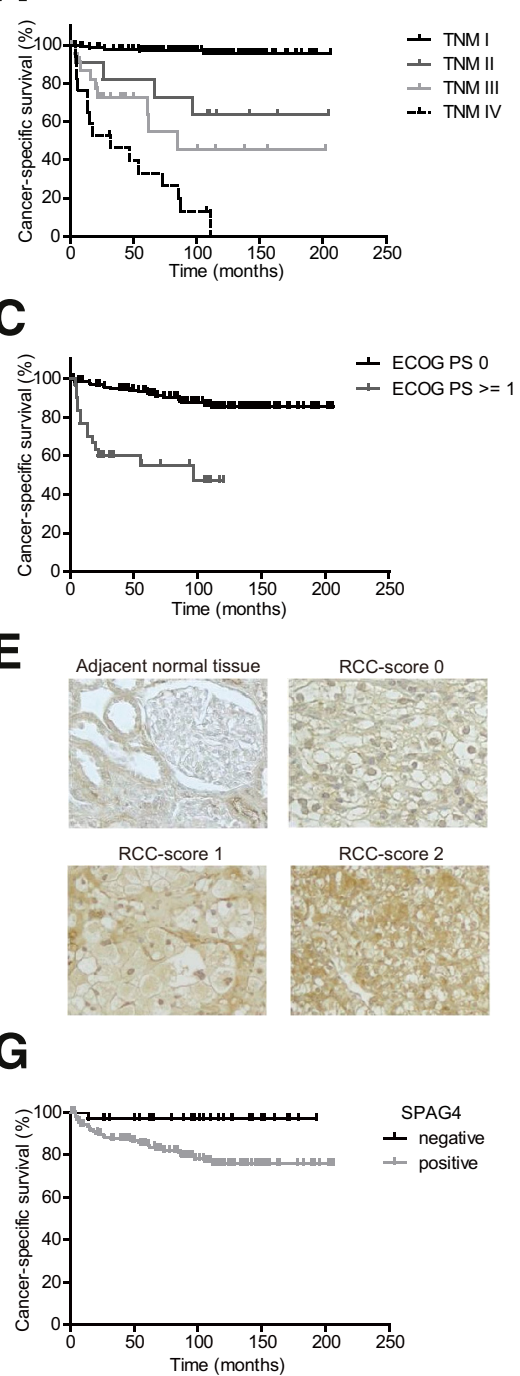

B

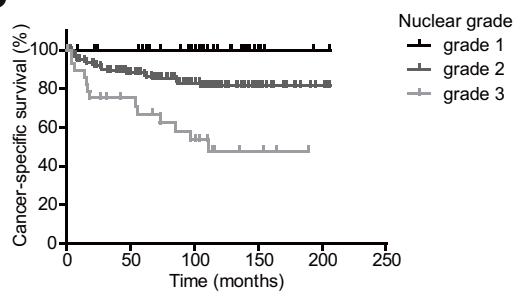

D

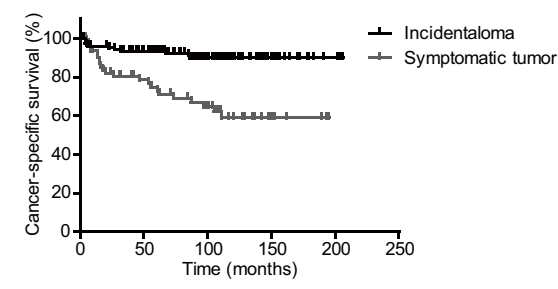

$\mathbf{F}$

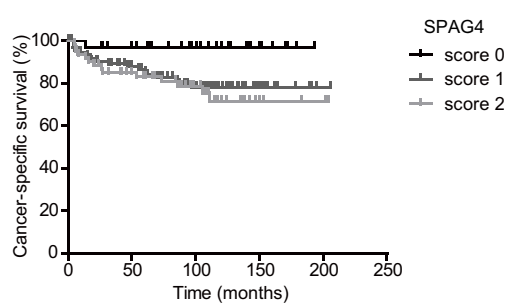

H

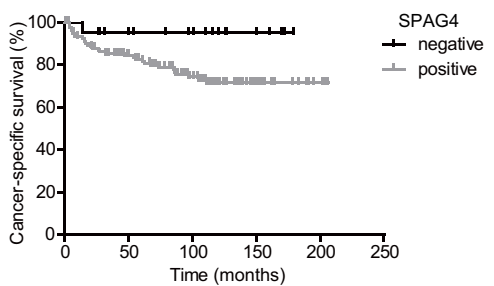

Figure 2 Expression of SPAG4 in $\mathrm{CCRCC}$ on tissue microarray. A-D: Kaplan-Meier analyses based on TNM staging (A), nuclear grading (B), ECOG PS (C), and mode of presentation (D) were performed for all 190 patient samples. All groups showed significantly different cancer-specific survival $(P<0.0001)$. E: Representative immunohistochemical images showing the expression of SPAG4 in adjacent normal kidney and representative images of negative (score 0 ), low (score 1 ) and high (score 2) SPAG4 staining in CCRCC. $\mathbf{F}$ and G: Kaplan-Meier analyses based on SPAG4 expression were performed in all 190 patients. Although the difference in cancer-specific mortality between SPAG4 score 1 and score 2 did not reach statistical significance $(P>0.05)(\mathbf{F})$, patients with SPAG4 expression (positive) showed significantly higher cancer-specific mortality than those without expression (negative) $(P=0.0215)(\mathbf{G})$. H: Kaplan-Meier analysis was performed in 155 patients whose nuclear grade was 2 or 3 . Patients with SPAG4 expression (positive) showed a trend toward poor cancer-specific mortality, compared with those without expression (negative) $(P=$ $0.065)$. Original magnification, $\times 200$.
Furthermore, we confirmed that SPAG4-mCherry showed the same localization as SPAG4-EGFP (Figure 3G).

Finally, to confirm the presence of SPAG4 at the intercellular bridge, HeLa cells were transfected with mCherrytagged SPAG4 plasmid and stained with anti- $\alpha$-tubulin antibody to identify the telophase cells (Figure $3 \mathrm{H}$ ). From microscopic observation of more than 2000 cells, we identified 23 telophase cells, of which 22 (96\%) exhibited SPAG4 at the intercellular bridge.

\section{SPAG4 Is Involved in Cytokinesis}

Given the localization of SPAG4 in the intercellular bridge, we speculated that SPAG4 plays a role in cytokinesis. We therefore studied the functional role of SPAG4 in cytokinesis in HeLa cells with SPAG4 knockdown. The knockdown efficiencies of two independent SPAG4 siRNAs (SPAG4-1 and SPAG4-2) at the mRNA level were 89\% and $82 \%$ under normoxia and $94 \%$ and $76 \%$ under hypoxia, respectively. Knockdown of SPAG4 was also confirmed at the protein level (Figure 4A).

Given that failure in cytokinesis leads to tetraploidization, we evaluated the number of tetraploid cells in nontreated HeLa cells by flow cytometry under both normoxia and hypoxia. Hypoxia increased the number of tetraploid cells significantly, compared with normoxia (Figure 4B). We also confirmed hypoxia-induced tetraploidization in control siRNA-treated HeLa cells (Figure 4C). Knockdown of SPAG4 by either of the two siRNAs independently increased the number of tetraploid cells under both normoxia and hypoxia (Figure 4C). This increase in tetraploidy by knockdown of SPAG4 paralleled the knockdown efficiency of the two siRNAs. Microscopic observation confirmed the increase of binucleated or multinucleated cells by SPAG4 knockdown (Figure 4D).

Given that cells with knockdown of SPAG4 exhibited dysregulated cell division, we investigated the effect of SPAG4 expression on cell proliferation. BrdU assay 
Table 2 Univariate and Multivariate Cox Proportional Hazards Model for the Predictive Factors of Cancer-Specific Survival

\begin{tabular}{|c|c|c|c|c|c|c|}
\hline \multirow[b]{2}{*}{ Variables } & \multicolumn{3}{|c|}{ Univariate analysis } & \multicolumn{3}{|c|}{ Multivariate analysis } \\
\hline & HR & $P$ value & $95 \% \mathrm{CI}$ & $\mathrm{HR}$ & $P$ value & $95 \% \mathrm{CI}$ \\
\hline \multicolumn{7}{|l|}{ All patients $(n=190)$} \\
\hline Age (years) & 1.02 & 0.32 & $0.99-1.05$ & 0.98 & 0.23 & $0.95-1.01$ \\
\hline SPAG4 (positive vs negative) & 7.30 & $0.0060^{*}$ & $1.57-129.89$ & 7.12 & $0.0116^{*}$ & $1.43-129.48$ \\
\hline Nuclear grade ( 3 vs $1+2)$ & 4.26 & $0.0002^{*}$ & $2.07-8.48$ & 1.33 & 0.52 & $0.55-3.07$ \\
\hline III & 18.28 & $<0.0001^{*}$ & $6.25-59.99$ & 14.00 & $<0.0001^{*}$ & $4.62-47.24$ \\
\hline IV & 48.01 & $<0.0001^{*}$ & $18.31-149.40$ & 23.04 & $<0.0001^{*}$ & $7.51-81.14$ \\
\hline ECOG PS ( $\geq 1$ vs 0$)$ & 6.36 & $<0.0001^{*}$ & $3.09-12.81$ & 3.82 & $0.0026^{*}$ & $1.60-9.31$ \\
\hline Symptomatic tumor vs incidentaloma & 4.43 & $<0.0001^{*}$ & $2.19-9.49$ & 1.53 & 0.35 & $0.63-3.82$ \\
\hline \multicolumn{7}{|l|}{ Patients of nuclear grade 2 or $3(n=155)$} \\
\hline \multicolumn{7}{|l|}{ TNM stage (reference $=$ stage $\mathrm{I}$ ) } \\
\hline II & 7.49 & $0.0067^{*}$ & $1.85-28.31$ & 6.44 & $0.0164^{*}$ & $1.45-26.54$ \\
\hline III & 13.89 & $<0.0001^{*}$ & $4.75-45.52$ & 11.44 & $<0.0001^{*}$ & $3.80-38.38$ \\
\hline IV & 35.44 & $<0.0001^{*}$ & $13.52-110.20$ & 17.17 & $<0.0001^{*}$ & $5.59-60.56$ \\
\hline ECOG PS ( $\geq 1$ vs 0 ) & 5.71 & $<0.0001^{*}$ & $2.77-11.48$ & 3.83 & $0.0023^{*}$ & $1.62-9.19$ \\
\hline Symptomatic tumor vs incidentaloma & 4.96 & $<0.0001^{*}$ & $2.45-10.64$ & 1.71 & 0.24 & $0.69-4.33$ \\
\hline
\end{tabular}

*Parameters examined in multivariate analysis: demographics (sex and age), SPAG4 score, nuclear grade, TNM stage, ECOG PS, and mode of presentation. $\mathrm{HR}$, hazard ratio.

indicated that the proliferation of SPAG4 siRNA-treated HeLa cells was significantly suppressed, compared with control siRNA-treated cells, under both normoxia and hypoxia (Figure 4E). MTS assay also indicated significantly fewer SPAG4 siRNA-treated HeLa cells than control siRNA-treated cells (Figure 4F). These observations were confirmed by cell number counting under a microscope (data not shown).

To confirm SPAG4 function in cytokinesis, we generated stable HeLa cell lines expressing fluorescent SPAG4 with mutations. Structurally, SPAG4 is composed of the $\mathrm{N}$-terminal domain, transmembrane domain, coiled-coil domain, and SUN domain. We generated five different mutants (Supplemental Figure S1) in which deletion of both $\mathrm{N}$-terminal domain and coiled-coil domain diminished SPAG4 localization at the intercellular bridge (Figure 4G) and induced cytokinesis failure, enhancing formation of binucleated or multinucleated cells (Supplemental Video S2). Microscopic observation confirmed a significant increase of binucleated or multinucleated cells in this deletion mutant (Figure 4H).

\section{Changes of Expression of Cytokinesis-Related Genes by Knockdown of SPAG4}

To investigate whether expression profiles of genes involved in cytokinesis are regulated by SPAG4, we performed DNA microarray analysis in HeLa cells treated with control siRNA or two independent siRNAs targeting SPAG4 (http:///www. ncbi.nlm.nih.gov/geo; accession number GSE46054). Functional annotation analysis (DAVID analysis) indicated that those genes which were up-regulated by SPAG4 knockdown $\left(>0.5 \log _{2}\right.$-fold up-regulated probes in the presence of SPAG4 siRNA, compared with control siRNA, under both normoxia and hypoxia) were associated with cell cycle and with chromosome segregation, and that these were significantly enriched (Tables 3 and 4). ${ }^{19,20}$ The 77 genes in the cell-cycle category are listed in Supplemental Table S5. This category includes genes involved in cytokinesis, such as Aurora A kinase (AURKA) and Aurora B kinase (AURKB), and the enrichment of cell cycle-related genes by knockdown of SPAG4 was also confirmed even in the DAVID functional annotation of KEGG-Kyoto Encyclopedia of Genes and Genomes pathways (enrichment score $\mathrm{ES}=6.04$; Benjamini and Hochberg false discovery rate $=1.10 \times$ $10^{-6}$ ) (Supplemental Table S6). ${ }^{37}$

\section{Discussion}

In the present study, we used ChIP-Seq analysis in combination with microarray analysis and identified SPAG4 as a novel HIF-1-specific target. RT-qPCR analysis showed upregulation of SPAG4 in hypoxic cells. Subcellular localization analysis indicated that SPAG4 localizes at the intercellular bridge in telophase, and functional studies demonstrated a crucial role of SPAG4 in cytokinesis. TMA analysis of 

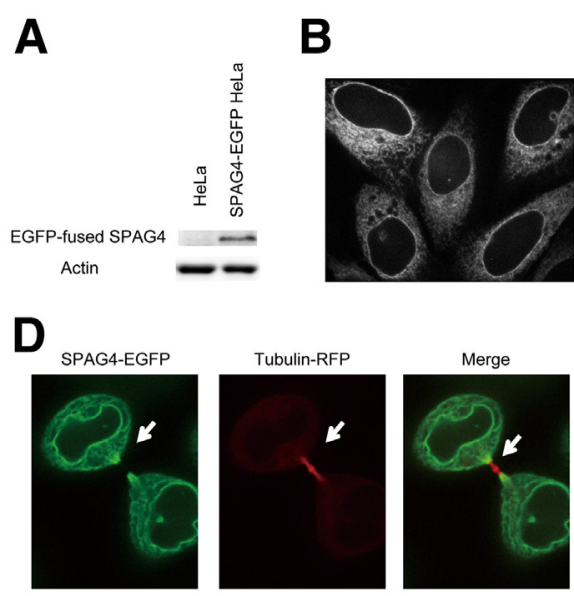

$\mathbf{F}$
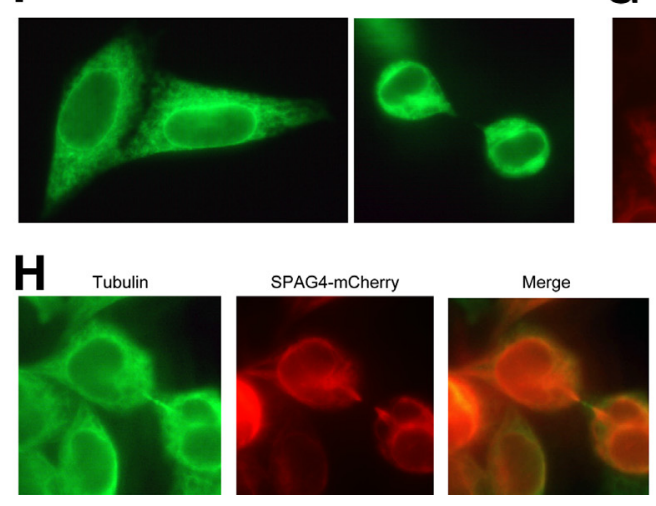

G
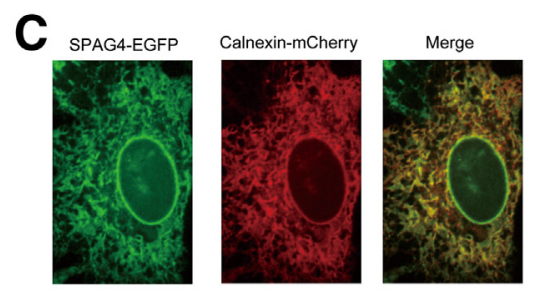

$\mathbf{E}$
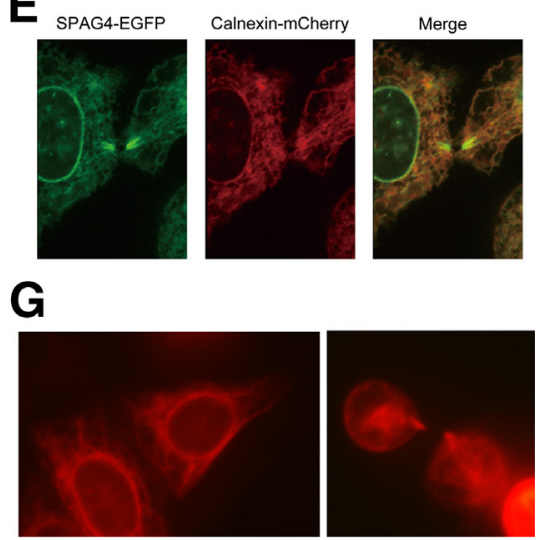

Figure 3 Live-cell imaging of SPAG4 in HeLa cells expressing fluorescent SPAG4. A: Immunoblotting analysis detected the EGFP-fused SPAG4 protein in SPAG4-EGFP HeLa clone. B: SPAG4 localization in interphase. C: Cells expressing SPAG4-EGFP and calnexin-mCherry confirmed localization of SPAG4 in the ER. D: SPAG4 localization during telophase. SPAG4-EGFP HeLa cells were transduced with red fluorescent tubulin to illustrate the midbody. SPAG4 localization to the intercellular bridge is indicated by an arrow. E: Cells expressing SPAG4EGFP and calnexin-mCherry showed that localization of SPAG4 at the base of the intercellular bridge was specific and independent of the ER. F: HeLa cells expressing c-Myc-tagged SPAG4 were fixed and stained with anti-c-Myc antibody. Cells are shown during interphase (left) and during telophase (right). G: HeLa cells were transiently transfected with SPAG4-mCherry plasmid. Cells are shown during interphase (left) and during telophase (right). H: HeLa cells were transiently transfected with SPAG4-mCherry plasmid and stained with anti- $\alpha$-tubulin antibody. Representative images of telophase cells are shown. Original magnification: $\times 1000(\mathbf{B}-\mathbf{E}) ; \times 400(\mathbf{F}-\mathbf{H})$. RFP; red fluorescent protein.

ccRCC demonstrated SPAG4 to be an independent prognostic factor. These findings suggest that SPAG4 may be upregulated to play a defensive role against hypoxia-induced polyploidy, which promotes survival of cancer cells under hypoxic conditions and thus leads to poor prognosis.

Although SPAG4 was originally identified as a testisspecific protein, ${ }^{9,10}$ recent studies have demonstrated ubiquitous expression of human SPAG4 in various normal tissues, including the kidney, at the mRNA level. ${ }^{14,15}$ Furthermore, SPAG4 mRNA is also detected in a wide range of neoplastic tissues, ${ }^{15,16}$ suggesting that SPAG4 expression may be a potential clinically relevant cancer marker, although the biological function remained to be elucidated.

Cytokinesis, the physical separation of two daughter cells during cell division, is the final stage of the cell cycle. ${ }^{38}$ Failure to complete cytokinesis can lead to formation of a persistent connection between the two daughter cells and subsequent tetraploidy, and tetraploidy is a genetically unstable state that promotes chromosomal instability, leading to eventual halt of proliferation and cell death. ${ }^{39,40}$

Localization of SPAG4 in the intercellular bridge, which was confirmed by SPAG4 with three different tags to exclude an artifact by tagging, suggested the involvement of SPAG4 in cytokinesis. Among 2000 cells transiently transfected with mCherry-tagged SPAG4 plasmid, 22/23 (96\%) telophase cells expressed SPAG4 at the intercellular bridge. For the small proportion of telophase cells that did not express SPAG4 at the intercellular bridge, we supposed that this was due to the overall low expression level of SPAG4-mCherry in these cells. We concluded that SPAG4 localizes at the intercellular bridge during telophase, involved in cytokinesis. Next, our knockdown studies of SPAG4 showed an increase in tetraploid cells, suggesting that SPAG4 may play a role in organized cytokinesis and prevent the formation of tetraploidy. Hypoxia increased the number of tetraploid cells in HeLa cell, compared with normoxia. A previous study had also demonstrated that exposure to acute hypoxia induced tetraploidization of diploid human tumor cells in vitro. ${ }^{41} \mathrm{We}$ speculate that SPAG4 in minute amounts serves a defensive role against tetraploidy under normoxia and is up-regulated by hypoxia to act as a safeguard against hypoxia-induced tetraploidy.

A functional role of SPAG4 in cytokinesis was confirmed by studies using mutated SPAG4. Although the precise molecular mechanism remains to be elucidated, our studies of deletion mutants support involvement of SPAG4 in cytokinesis, showing that both $\mathrm{N}$-terminal domain and coiled-coil domain are essential to induce intact cytokinesis.

We also showed that knockdown of SPAG4 changed the expression level of genes involved in cytokinesis, including AURKA and AURKB. ${ }^{42}$ Because SPAG4 is localized at the intercellular bridge, its role in cytokinesis likely directly influences the mechanics of cell division. The completion of 
A

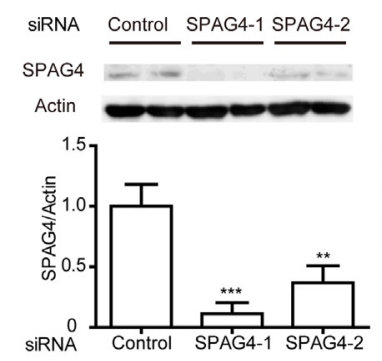

B

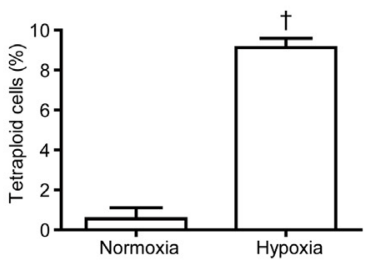

C
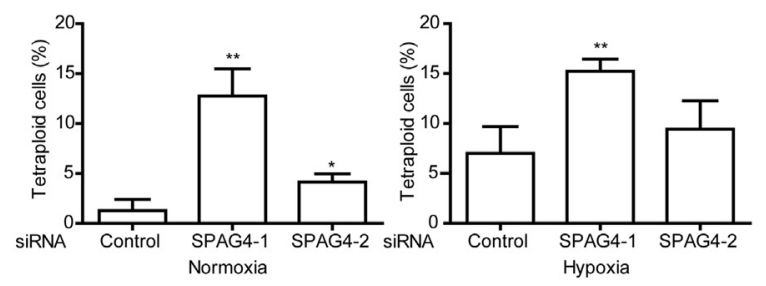

E

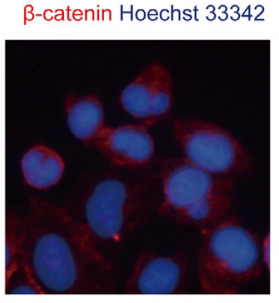

SPAG4 siRNA-treated HeLa

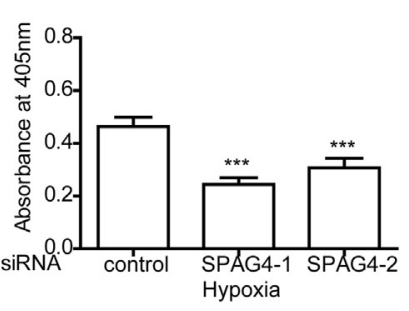

yypoxia

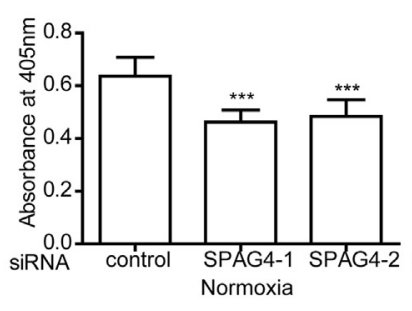

H
F

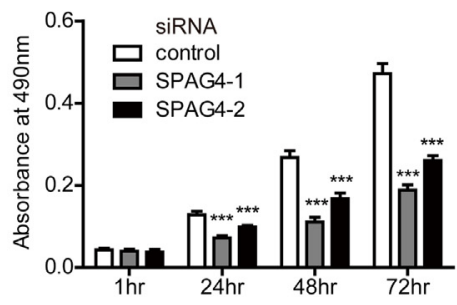

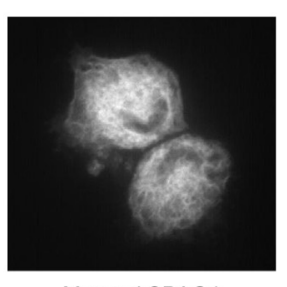

Mutated SPAG4

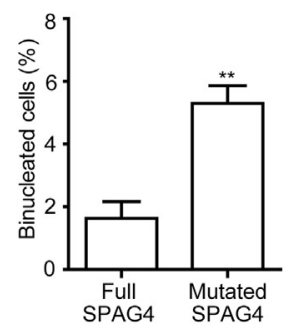
SPAG4 SPAG4
G

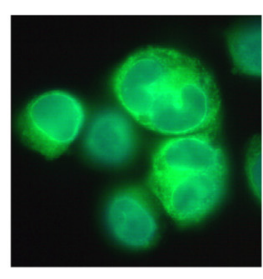

Mutated SPAG4

Figure 4 SPAG4 plays a defensive role against hypoxia-induced polyploidy. A: SPAG4 siRNA decreased SPAG4 protein expression at 48 hours after transfection in HeLa cells. Data are expressed as ratios of SPAG4 and actin band intensity, standardized to the mean of the control siRNA, under normoxia. B: Flow cytometric analysis in HeLa cells showed that the proportion of tetraploid cells increased under hypoxia, compared with normoxia. C: Flow cytometric analysis in HeLa cells showed that the proportion of tetraploid cells increased in SPAG4 siRNA-treated HeLa cells, compared with control siRNA-treated cells, under normoxia (left) and hypoxia (right). D, left: Microscopic observation revealed a significant increase in binucleated and multinucleated cells in cells treated with SPAG4 siRNA (SPAG4-1) under normoxia. Cells were fixed and stained with anti- $\beta$-catenin antibody and Hoechst 33342 dye to visualize cell membranes and nuclei. At least 300 cells were counted in each group, and three independent experiments were performed. D, right. A representative image of binucleated cells treated with SPAG4 siRNA (SPAG4-1) under normoxia is shown. E: BrdU assay showed that knockdown of SPAG4 significantly decreased intake of BrdU under both normoxia (left) and hypoxia (right). F: MTS assay showed that the number of living cells was significantly less in SPAG4 siRNA-treated cells under normoxia. G: Mutated SPAG4-EGFP, in which both N-terminal domain and coiled-coil domain were deleted, failed to localize at the intercellular bridge. H, left: Microscopic observation revealed a significant increase in binucleated or multinucleated cells in cells expressing mutated SPAG4-EGFP (in which both $\mathrm{N}$-terminal domain and coiled-coil domain were deleted). At least 300 cells were counted in each group, and three independent experiments were performed. $\mathbf{H}$, right: A representative image of binucleated cells in deletion mutant. Data are expressed as means \pm SD. $n=4(\mathbf{A}$ and $\mathbf{B})$ or $6(\mathbf{E}$ and $\mathbf{F})$. ${ }^{*} P<0.05,{ }^{*} P<$ $0.01,{ }^{* *} P<0.001$, and ${ }^{\dagger} P<0.0001$ versus control siRNA or normoxia. Original magnification: $\times 400(\mathbf{D}$ and $\mathbf{H}) ; \times 1000(\mathbf{G})$.

cytokinesis requires the precise and coordinated regulation of the genes involved, and we speculate that abnormal cytokinesis by SPAG4 knockdown resulted in the dysregulation of the cytokinesis-related genes.

Knockdown of SPAG4 suppressed cell proliferation. It is widely acknowledged that the proliferation of tetraploid cells is limited by a variety of mechanisms. ${ }^{40}$ Tetraploid cells arrest their cell cycle, and this arrest depends on the tumor suppressor protein p53. ${ }^{43-45}$ Even in transformed cell lines with p53-defective pathways (which includes HeLa cells), cleavage failure can also be lethal, via failure of further cleavage and eventual cell death. ${ }^{39}$ In a study exploring the consequences of binucleation, binucleated
HeLa cells showed delay in cell-cycle progression and more cell death, compared with their mononucleated counterparts. ${ }^{46}$ In the present study, we observed that knockdown of SPAG4 increased tetraploidy of the cultured cells, resulting in subsequent suppression of cell proliferation due to disturbance of cell division.

To clarify clinical relevance of SPAG4, we studied ccRCC, which is the most common malignancy of the kidney in humans. ${ }^{47}$ Half of the patients who undergo resection with a curative intent are expected to have a relapse during the course of the disease, and metastatic $\mathrm{RCC}$ is one of the most treatment-resistant malignancies. ${ }^{48}$ HIF- $1 \alpha$ and HIF- $2 \alpha$ are overexpressed in the majority of 
Table 3 Functional Annotation Clustering by DAVID Analysis

\begin{tabular}{|c|c|c|}
\hline Functional annotation & $\begin{array}{l}\text { Gene } \\
\text { number }\end{array}$ & FDR \\
\hline \multicolumn{3}{|l|}{ Cluster $1(\mathrm{ES}=23.90)$} \\
\hline Cell-cycle phase & 58 & $9.67 \times 10^{-25}$ \\
\hline Cell cycle & 77 & $1.60 \times 10^{-24}$ \\
\hline M phase & 51 & $8.26 \times 10^{-24}$ \\
\hline Cell cycle process & 64 & $4.32 \times 10^{-23}$ \\
\hline M phase of mitotic cell cycle & 42 & $1.52 \times 10^{-22}$ \\
\hline Mitotic cell cycle & 52 & $1.30 \times 10^{-22}$ \\
\hline Mitosis & 41 & $5.56 \times 10^{-22}$ \\
\hline Nuclear division & 41 & $5.56 \times 10^{-22}$ \\
\hline Organelle fission & 41 & $2.34 \times 10^{-21}$ \\
\hline Cell division & 37 & $8.19 \times 10^{-14}$ \\
\hline \multicolumn{3}{|l|}{ Cluster $2(\mathrm{ES}=8.86)$} \\
\hline DNA metabolic process & 42 & $7.26 \times 10^{-10}$ \\
\hline Response to DNA damage stimulus & 32 & $1.61 \times 10^{-07}$ \\
\hline DNA repair & 27 & $4.31 \times 10^{-07}$ \\
\hline Cellular response to stress & 36 & $1.60 \times 10^{-05}$ \\
\hline \multicolumn{3}{|l|}{ Cluster $3(E S=6.32)$} \\
\hline Regulation of cell cycle & 30 & $1.57 \times 10^{-07}$ \\
\hline Regulation of mitotic cell cycle & 19 & $2.16 \times 10^{-06}$ \\
\hline Regulation of cell cycle process & 16 & $7.66 \times 10^{-06}$ \\
\hline Cell cycle checkpoint & 13 & $1.17 \times 10^{-04}$ \\
\hline Regulation of mitosis & 10 & $4.08 \times 10^{-04}$ \\
\hline Regulation of nuclear division & 10 & $4.08 \times 10^{-04}$ \\
\hline Regulation of organelle organization & 17 & 0.0034 \\
\hline \multicolumn{3}{|l|}{ Cluster $4(E S=4.58)$} \\
\hline Microtubule-based process & 23 & $1.31 \times 10^{-05}$ \\
\hline Microtubule cytoskeleton organization & 15 & $6.48 \times 10^{-04}$ \\
\hline Spindle organization & 8 & 0.0043 \\
\hline \multicolumn{3}{|l|}{ Cluster $5(E S=2.95)$} \\
\hline Chromosome segregation & 17 & $8.36 \times 10^{-09}$ \\
\hline Mitotic sister chromatid segregation & 10 & $1.09 \times 10^{-05}$ \\
\hline Sister chromatid segregation & 10 & $1.33 \times 10^{-05}$ \\
\hline $\begin{array}{l}\text { Establishment of chromosome } \\
\text { localization }\end{array}$ & 5 & 0.0176 \\
\hline Chromosome localization & 5 & 0.0176 \\
\hline
\end{tabular}

Genes up-regulated by SPAG4 knockdown were clustered by gene ontology (biological process). ES $\geq 1.5$ was considered significant.

FDR, Benjamini and Hochberg false discovery rates (5\% false positive discovery rate).

ccRCCs, and some studies reported that patients with high HIF- $1 \alpha$ expression had significantly worse survival than

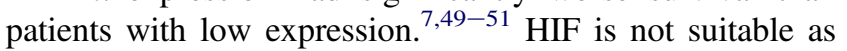
a clinical prognostic marker, however, because its very short half-life period (less than 5 minutes) allows degradation of the protein during processing of tissue samples. ${ }^{2}$ Thus, the need remains for biomarkers to improve diagnosis, identify tumors with a high risk of recurrence, allow easier followup, suggest earlier adjuvant treatment, and select the best treatment option for metastatic patients in renal oncology.

We performed TMA analysis with 190 ccRCC samples. We observed relatively few cancer-specific deaths in our study population, because most patients $(72.6 \%)$ were classified at TNM stage I. It is likely that our university hospital is a flagship hospital of cancer treatments, and that many patients with early-stage cancer who need surgery are referred from regional hospitals. Although cancer-specific survival for the whole group was good, 5-year cancerspecific survival for TNM stages I through IV (96.9\%, $72.7 \%, 63.7 \%$, and $26.5 \%$, respectively) were equivalent to those reported previously. ${ }^{32}$

Our TMA analysis of ccRCC demonstrated for the first time that SPAG4 expression is associated with higher cancer-specific mortality. Although SPAG4 expression was associated with higher nuclear grading, which is a wellknown prognostic factor in ccRCC, ${ }^{32,33,35,36}$ SPAG4 was an independent prognostic factor in multivariate analysis after correction for TNM stage, nuclear grade, ECOG PS, and mode of presentation. In addition, even in patients with nuclear grade 2 or 3 , who have a poor prognosis, SPAG4 expression can predict worse cancer-specific survival. Thus, SPAG4 may be a clinically relevant cancer marker in the prediction of poor survival. Although there was statistical significance in our study, the relatively small number of SPAG4 nonexpressors is a potential limitation of our study. Further study in a larger population is needed to establish the usefulness of SPAG4 as a marker. In ccRCC, carbonic anhydrase 9 (CA9) is one of the most studied and most promising biomarkers. ${ }^{51}$ Patients with low CA9 expression were reported to have worse prognosis; in metastatic disease, high CA9 expression was associated with better survival. ${ }^{51}$ SPAG4 could be a clinically useful biomarker in combination with other biomarkers, such as CA9.

SPAG4 belongs to the SUN family of proteins, which contain the SUN domain. ${ }^{11-13}$ Most SUN-domain proteins are localized at the inner nuclear membrane, but in previous reports SPAG4 did not localize specifically at the nuclear envelope but instead localized throughout the ER, ${ }^{13,52}$ which is consistent with the present results. A function of SPAG4 in the ER is beyond the scope of the current investigation, however, and remains a subject for future study.

In conclusion, we have identified SPAG4 as a novel HIF-1 target that plays a crucial role in cytokinesis. SPAG4 is up-regulated to play a defensive role against hypoxia-

Table 4 Representative Genes for the Five Cluster Categories

\begin{tabular}{llr}
\hline Category & Genes & Enrichment score \\
\hline Cell cycle & AURKA, AURKB, BIRC5, CCNA2, CCNB1, CDC20, CDK1 (previously CDC2), CEP55 & 23.9 \\
DNA metabolic process & EX01, NFIC, PARP2, POLK (alias POLQ), RFC3, RFC4 & 8.86 \\
Regulation of cell cycle & AURKAIP1 (alias AKIP), BUB1, CDKN3, CHEK1, PLK4 & 6.32 \\
Microtubule-based process & CENPA, CKAP5, KIF2C, KIF9, KIF14, KIF18B, KIF20A & 4.58 \\
Chromosome segregation & CENPE, CENPO, ESPL1 & 2.95 \\
\hline
\end{tabular}


induced polyploidy, which promotes survival of cancer cells under hypoxic conditions and leads to poor prognosis.

\section{Acknowledgment}

We thank Dr. Teppei Morikawa (University of Tokyo) for constructing the TMA.

\section{Supplemental Data}

Supplemental material for this article can be found at http://dx.doi.org/10.1016/j.ajpath.2013.02.024.

\section{References}

1. Brown JM, Giaccia AJ: The unique physiology of solid tumors: opportunities (and problems) for cancer therapy. Cancer Res 1998, 58:1408-1416

2. Semenza GL: Regulation of mammalian $\mathrm{O} 2$ homeostasis by hypoxiainducible factor 1. Annu Rev Cell Dev Biol 1999, 15:551-578

3. Berra E, Benizri E, Ginouvès A, Volmat V, Roux D, Pouysségur J: HIF prolyl-hydroxylase 2 is the key oxygen sensor setting low steadystate levels of HIF-1alpha in normoxia. EMBO J 2003, 22: 4082-4090

4. Cockman ME, Masson N, Mole DR, Jaakkola P, Chang GW, Clifford SC, Maher ER, Pugh CW, Ratcliffe PJ, Maxwell PH: Hypoxia inducible factor-alpha binding and ubiquitylation by the von Hippel-Lindau tumor suppressor protein. J Biol Chem 2000, 275: 25733-25741

5. Zhong H, De Marzo AM, Laughner E, Lim M, Hilton DA, Zagzag D, Buechler P, Isaacs WB, Semenza GL, Simons JW: Overexpression of hypoxia-inducible factor 1alpha in common human cancers and their metastases. Cancer Res 1999, 59:5830-5835

6. Talks KL, Turley H, Gatter KC, Maxwell PH, Pugh CW, Ratcliffe PJ, Harris AL: The expression and distribution of the hypoxia-inducible factors HIF-1alpha and HIF-2alpha in normal human tissues, cancers, and tumor-associated macrophages. Am J Pathol 2000, 157:411-421

7. Klatte T, Seligson DB, Riggs SB, Leppert JT, Berkman MK, Kleid MD, Yu H, Kabbinavar FF, Pantuck AJ, Belldegrun AS: Hypoxia-inducible factor 1 alpha in clear cell renal cell carcinoma. Clin Cancer Res 2007, 13:7388-7393

8. Semenza GL: Targeting HIF-1 for cancer therapy. Nat Rev Cancer 2003, 3:721-732

9. Shao X, Tarnasky HA, Lee JP, Oko R, van der Hoorn FA: Spag4, a novel sperm protein, binds outer dense-fiber protein Odf1 and localizes to microtubules of manchette and axoneme. Dev Biol 1999, 211:109-123

10. Tarnasky H, Gill D, Murthy S, Shao X, Demetrick DJ, van der Hoorn FA: A novel testis-specific gene, SPAG4, whose product interacts specifically with outer dense fiber protein ODF27, maps to human chromosome 20q11.2. Cytogenet Cell Genet 1998, 81:65-67

11. Tzur YB, Wilson KL, Gruenbaum Y: SUN-domain proteins: 'Velcro' that links the nucleoskeleton to the cytoskeleton. Nat Rev Mol Cell Biol 2006, 7:782-788

12. Razafsky D, Hodzic D: Bringing KASH under the SUN: the many faces of nucleo-cytoskeletal connections. J Cell Biol 2009, 186: 461-472

13. Hasan $S$, Güttinger $S$, Mühlhäusser $P$, Anderegg $F$, Bürgler $S$, Kutay U: Nuclear envelope localization of human UNC84A does not require nuclear lamins. FEBS Lett 2006, 580:1263-1268

14. Siliņa K, Zayakin P, Kalniņa Z, Ivanova L, Meistere I, Endzeliņš E, Abols A, Stengrēvics A, Leja M, Ducena K, Kozirovskis V, Linē A: Sperm-associated antigens as targets for cancer immunotherapy: expression pattern and humoral immune response in cancer patients. J Immunother 2011, 34:28-44

15. Kennedy C, Sebire K, de Kretser DM, O'Bryan MK: Human sperm associated antigen 4 (SPAG4) is a potential cancer marker. Cell Tissue Res 2004, 315:279-283

16. Condomines M, Hose D, Rème T, Requirand G, Hundemer M, Schoenhals M, Goldschmidt H, Klein B: Gene expression profiling and real-time PCR analyses identify novel potential cancer-testis antigens in multiple myeloma. J Immunol 2009, 183:832-840

17. Mimura I, Nangaku M, Kanki Y, Tsutsumi S, Inoue T, Kohro T, Yamamoto S, Fujita T, Shimamura T, Suehiro J, Taguchi A, Kobayashi M, Tanimura K, Inagaki T, Tanaka T, Hamakubo T, Sakai J, Aburatani H, Kodama T, Wada Y: Dynamic change of chromatin conformation in response to hypoxia enhances the expression of GLUT3 (SLC2A3) by cooperative interaction of hypoxia-inducible factor 1 and KDM3A. Mol Cell Biol 2012, 32: 3018-3032

18. Valouev A, Johnson DS, Sundquist A, Medina C, Anton E, Batzoglou S, Myers RM, Sidow A: Genome-wide analysis of transcription factor binding sites based on ChIP-Seq data. Nat Methods 2008, 5:829-834

19. Huang DW, Sherman BT, Lempicki RA: Systematic and integrative analysis of large gene lists using DAVID bioinformatics resources. Nat Protoc 2009, 4:44-57

20. Huang DW, Sherman BT, Lempicki RA: Bioinformatics enrichment tools: paths toward the comprehensive functional analysis of large gene lists. Nucleic Acids Res 2009, 37:1-13

21. Chiang CK, Tanaka T, Inagi R, Fujita T, Nangaku M: Indoxyl sulfate, a representative uremic toxin, suppresses erythropoietin production in a HIF-dependent manner. Lab Invest 2011, 91:1564-1571

22. Tanaka T, Miyata $T$, Inagi R, Fujita $T$, Nangaku M: Hypoxia in renal disease with proteinuria and/or glomerular hypertension. Am J Pathol 2004, 165:1979-1992

23. Tanaka T, Yamaguchi J, Shoji K, Nangaku M: Anthracycline inhibits recruitment of hypoxia-inducible transcription factors and suppresses tumor cell migration and cardiac angiogenic response in the host. J Biol Chem 2012, 287:34866-34882

24. Eble JN, Sauter G, Epstein JI, Sesterhenn IA (Eds): Pathology \& Genetics of Tumours of the Urinary System and Male Genital Organs. World Health Organization Classification of Tumours. Lyon, IARC Press, 2004, pp 23-25

25. Sobin L, Gospodarowicz M, Wittekind C: TNM Classification of Malignant Tumors. Chichester, UK, Wiley-Blackwell, 2009

26. The Japanese Urological Association, The Japanese Society of Pathology, Japan Radiological Society: General Rule for Clinical and Pathological Studies on Renal Cell Carcinoma. ed 4. Tokyo, Japan, Kanehara, 2011

27. Oken MM, Creech RH, Tormey DC, Horton J, Davis TE, McFadden ET, Carbone PP: Toxicity and response criteria of the Eastern Cooperative Oncology Group. Am J Clin Oncol 1982, 5:649-655

28. Lee CT, Katz J, Fearn PA, Russo P: Mode of presentation of renal cell carcinoma provides prognostic information. Urol Oncol 2002, 7 : $135-140$

29. Ohse T, Pippin JW, Vaughan MR, Brinkkoetter PT, Krofft RD, Shankland SJ: Establishment of conditionally immortalized mouse glomerular parietal epithelial cells in culture. J Am Soc Nephrol 2008, 19:1879-1890

30. Shu X, Shaner NC, Yarbrough CA, Tsien RY, Remington SJ: Novel chromophores and buried charges control color in mFruits. Biochemistry 2006, 45:9639-9647

31. Kobayashi T, Murayama T: Cell cycle-dependent microtubule-based dynamic transport of cytoplasmic dynein in mammalian cells. PLoS One 2009, 4:e7827

32. Gudbjartsson T, Hardarson S, Petursdottir V, Thoroddsen A, Magnusson J, Einarsson GV: Histological subtyping and nuclear grading of renal cell carcinoma and their implications for survival: a retrospective nation-wide study of 629 patients. Eur Urol 2005, 48:593-600 
33. Sun M, Lughezzani G, Jeldres C, Isbarn H, Shariat SF, Arjane P, Widmer H, Pharand D, Latour M, Perrotte P, Patard JJ, Karakiewicz PI: A proposal for reclassification of the Fuhrman grading system in patients with clear cell renal cell carcinoma. Eur Urol 2009, 56:775-781

34. Zisman A, Pantuck AJ, Dorey F, Said JW, Shvarts O, Quintana D, Gitlitz BJ, deKernion JB, Figlin RA, Belldegrun AS: Improved prognostication of renal cell carcinoma using an integrated staging system. J Clin Oncol 2001, 19:1649-1657

35. Minardi D, Lucarini G, Mazzucchelli R, Milanese G, Natali D, Galosi AB, Montironi R, Biagini G, Muzzonigro G: Prognostic role of Fuhrman grade and vascular endothelial growth factor in pT1a clear cell carcinoma in partial nephrectomy specimens. J Urol 2005, 174:1208-1212

36. Rioux-Leclercq N, Karakiewicz PI, Trinh QD, Ficarra V, Cindolo L, de la Taille A, Tostain J, Zigeuner R, Mejean A, Patard JJ: Prognostic ability of simplified nuclear grading of renal cell carcinoma. Cancer 2007, 109:868-874

37. Goto S, Bono H, Ogata H, Fujibuchi W, Nishioka T, Sato K, Kanehisa M: Organizing and computing metabolic pathway data in terms of binary relations. Pac Symp Biocomput 1997:175-186

38. Eggert US, Mitchison TJ, Field CM: Animal cytokinesis: from parts list to mechanisms. Annu Rev Biochem 2006, 75:543-566

39. Krzywicka-Racka A, Sluder G: Repeated cleavage failure does not establish centrosome amplification in untransformed human cells. J Cell Biol 2011, 194:199-207

40. Ganem NJ, Pellman D: Limiting the proliferation of polyploid cells. Cell 2007, 131:437-440

41. Rofstad EK, Johnsen NM, Lyng H: Hypoxia-induced tetraploidisation of a diploid human melanoma cell line in vitro. Br J Cancer Suppl 1996, 27:S136-S139

42. Marumoto T, Zhang D, Saya H: Aurora-A-a guardian of poles. Nat Rev Cancer 2005, 5:42-50

43. Cross SM, Sanchez CA, Morgan CA, Schimke MK, Ramel S, Idzerda RL, Raskind WH, Reid BJ: A p53-dependent mouse spindle checkpoint. Science 1995, 267:1353-1356
44. Vogel C, Kienitz A, Hofmann I, Müller R, Bastians H: Crosstalk of the mitotic spindle assembly checkpoint with p53 to prevent polyploidy. Oncogene 2004, 23:6845-6853

45. Castedo M, Coquelle A, Vivet S, Vitale I, Kauffmann A, Dessen P, Pequignot MO, Casares N, Valent A, Mouhamad S, Schmitt E, Modjtahedi N, Vainchenker W, Zitvogel L, Lazar V, Garrido C, Kroemer G: Apoptosis regulation in tetraploid cancer cells. EMBO J 2006, 25:2584-2595

46. Shi Q, King RW: Chromosome nondisjunction yields tetraploid rather than aneuploid cells in human cell lines. Nature 2005, 437:1038-1042

47. Laber DA: Risk factors, classification, and staging of renal cell cancer. Med Oncol 2006, 23:443-454

48. Tanji N, Yokoyama M: Treatment of metastatic renal cell carcinoma and renal pelvic cancer. Clin Exp Nephrol 2011, 15:331-338

49. Lidgren A, Hedberg Y, Grankvist K, Rasmuson T, Vasko J, Ljungberg B: The expression of hypoxia-inducible factor 1alpha is a favorable independent prognostic factor in renal cell carcinoma. Clin Cancer Res 2005, 11:1129-1135

50. Biswas S, Charlesworth PJ, Turner GD, Leek R, Thamboo PT, Campo L, Turley H, Dildey P, Protheroe A, Cranston D, Gatter KC, Pezzella F, Harris AL: CD31 angiogenesis and combined expression of HIF-1alpha and HIF-2alpha are prognostic in primary clear-cell renal cell carcinoma (CC-RCC), but HIFalpha transcriptional products are not: implications for antiangiogenic trials and HIFalpha biomarker studies in primary CC-RCC. Carcinogenesis 2012, 33:1717-1725

51. Schultz L, Chaux A, Albadine R, Hicks J, Kim JJ, De Marzo AM, Allaf ME, Carducci MA, Rodriguez R, Hammers HJ, Argani P, Reuter VE, Netto GJ: Immunoexpression status and prognostic value of mTOR and hypoxia-induced pathway members in primary and metastatic clear cell renal cell carcinomas. Am J Surg Pathol 2011, 35:1549-1556

52. Turgay $Y$, Ungricht R, Rothballer A, Kiss A, Csucs G, Horvath $P$, Kutay U: A classical NLS and the SUN domain contribute to the targeting of SUN2 to the inner nuclear membrane. EMBO J 2010, 29: $2262-2275$ 